\title{
Seeing a Risk
}

Stephen J. Smith

University of Alberta

I dare you to

Go on, Go on

I dare you to.

Bet you can't

You're too afraid

Go on-I dare you to.

\section{The Dare}

Hazards loom large when we are dared to do something. The dare exposes us to the chance of injury or loss in spite of what we might be thinking. It requires of us a response. As we look further at the situation the context of risk becomes appreciated. We may see mischief, for instance, in the other's way of pointing, of taunting, of provoking a response. The dare disturbs our present security, for not to accept the challenge contained within the dare is to court failure and possible ridicule, yet to respond to the dare is also to risk failure in addition to the chance of getting hurt. We fear we must take a risk either way.

We are dared! We feel obliged to act in some way. Of course we could always rush in blindly and simply hope for the best. But such foolhardiness may only see risk from the perspective of the other who dares us, who shows us a danger. We are spellbound as it were by the dare. And suppose we ignore the mischief in the other's words, or maybe relish in it because the dare holds out the possibility of recognition or of showing off. Our blindness to the situation and to the dangers lurking there yields a false trust in another person. On this score it is worth remembering that the word "danger" actually derives from the late Latin "dominiarium," meaning dominion or rule (Shipley, 1959, p. 107). Through the dare we are subject to the other's will.

How can we ignore the dare? Seeing the other perched above us, calling us up, daring us to climb even higher means there can be no going back. The very presence of this person obliges us to see risk. However the dare is not always articulated in so many words. It imposes itself in other ways. Visualize with me a little dam in the Coomera valley, its spillway now completely moss-covered from the summer dryness. Watch as some brave souls dive from the top of the pumping station and then with a few bold strokes swim to the edge of the spillway. We see them slide over the edge and hear the whoops 
and hollers as they plummet to the reservoir below. It is a relief to see them surface unscathed, yet as they clamber up the track that leads back to the pumping station intent on repeating this risky slide, we feel the need to have a go ourselves. Maybe it is too soon. We watch some more until a nervous intensity wells within us. It is now or never. A dare has taken shape. And as we waver at the top of the spillway while others have their turn, the need to prove ourselves is overpowering. We, too, must take a risk.

The dare is not the only way of encountering risk. Roche (1980) says: "Gambling as a movement represents an affirmation not of outcomes, per se, but rather their unpredictability; it thus represents the notion of taking a risk" (p. 79). Risk can also be met in obstacles during a task, by seeking out adventure, or by simply taking our chances stepping out onto the street; and the meaning of risk would depend upon these various ways it enters our lives. The dare is significant primarily because it draws attention to risk and exposes us to the possibilities of experiencing it. The dare provokes a response. It provokes by suggesting our limitations, but also admonishes us not to accept our limits and thus to test them. The dare instructs us to look more closely at what taking a risk entails.

A mountain climber says "There's risk, to be sure, but it's a highly calculated risk, much more so than driving a car. You relate the risks involved to your own experience and that suggests the number and kinds of precautions you must take" (Csikszentmihalyi, 1975, p. 84). But one cannot simply weigh the risks involved against one's capacity for action-still the climber must act with daring, still there remains an element of risk which cannot be calculated away. As the climber admits: "Beyond that (calculating risk), there is always the unknown which is simply there and nothing can be done about it" (p. 84). The risks of climbing are ultimately beyond a calculated response. The climber must risk certainty. To take a risk requires that the "unknown" be encountered-that we do indeed experience uncertainty. We are required to do more than what feels comfortable, more than simply display those "capabilities" we have. We must dig deep within ourselves and test the limits of our resources. Taking a risk is the project of encountering the "unknown" wherein self-understanding occurs.

The likely origin of to take a risk is "to navigate among cliffs" such that one is at risk by being open to danger, loss or hurt (Weekley, 1924 , xii). This origin provides cause for speaking presently of risktaking as a responding to the challenge of cliffs, rocks, mountains and outdoor terrains, and of climbing as perhaps a paradigm example of risk taking. Through this focus the child's experience of risk might be seen. How might we understand children taking risks? The question is not simple. It moves beyond the notion of the dare which was our pedagogical starting point. On the basis of a thoughtful interest in children: What might risk taking mean for the child? 
How should children respond to risk? How should we respond to them? What does seeing a risk respons-ibly mean?

\section{Becoming Mindful}

From childhood we recall a newly painted climbing frame, a jungle gym, over in the park. It shares a space with the see-saw, the slippery slide and a few lesser pieces; a space which is defined not only by the ant-bed dirt which has been spread over the worn out ground, but also by the contrast it provides with the rest of the park. This play equipment presides over a large parkland that stretches over a bank to the river on one side and down to the duck pond on the other. To climb this frame is to be king of the castle and indeed this estate.

This climbing frame is what we run to first. Hanging onto the lowest bars is not enough. We have to climb it. Dad stands underneath, arms up watching for the sudden slip, while we through effort, concentration and the occasional assist are soon standing atop the frame. The raised centrepiece then allows for movement around the top. "Be careful, be careful" we hear, but already we are beyond the grasp of the outstretched arms below, and do not want it otherwise. Sometime later the climbing frame loses its attraction. The slippery slide takes our fancy, but now we refuse to come down in a seated position. We prefer to lie on our stomach and hold the sides so that we can brake the slide at will, and so that we can feel the loss and then the regaining of our attachment to the slide. Though they tempt us to come down seated as we used to, it is to no avail, unless they come down with us and even then we are not so sure. So what has changed that we no longer unwittingly climb so high? No longer do we stand on top peering down as if without a care. No longer do we send a shudder through that adult standing below.

The child must come to terms with these playthings in the park. Though they beckon the child, it is in a way that might very well pull the child away from the adult and that secure place where the adult stands. The climbing frame and the slippery slide look over this place. They afford a view of the one who would otherwise be looking over the child - a view which can create a profound sense of distance between child and adult. The higher the child climbs the more distant he becomes from the familiar world. Moreover, the higher the child climbs the more he feels the concern, the pull, of the adult below. The climbing frame and the slippery slide must be treated carefully.

We see such children in the playground become aware of the risks of their activity. We look at the hesitancy that attends their movements. We see them become fearful, perhaps even afraid. Children are done a grave disservice if we left the matter there, for their fearfulness is related to our efforts to become mindful of them. In other words, it is not sufficient to say that children become fearful if our observation explains away their actions and avoids the question of 
our responsibility for their state-of-mind; to the contrary, we imagine ourselves taking a risk when we look at fearful children. We watch as they navigate between the familiar and the unknown, we share in their discoveries, and we share their failures. Their apprehension strikes at the heart of our concern for them. Becoming fearful signifies our relation to children, our fearing for them, and as well, our becoming mindful of how the world appears to them.

We see the child as he or she courts fear. The fearsome object, that which is disclosed as the object of fear, can be approached in various ways. The child responds in his own way. He swings on the low bars of the climbing frame and controls his fall on the slippery slide. Either way a sense of security comes with these more tentative responses to this play equipment. With use the equipment becomes less distant and increasingly familiar. The child's fear of the distant and unknown becomes a questioning of both the world and his place within it. If we close our eyes to this child's fear then there is the danger of his becoming truly afraid, incapable of taking a risk at all. We remember this from the slippery slide where any admonishment serves only as a provocation to which the child is even less likely to respond. This dare to come down the slide only accentuates fear, making him afraid of the slide. We must simply wait for the child to see for himself what the slide involves. To do otherwise is to jeopardize this possibility of self-disclosure and turn attention to those possibilities that encapsulate a fearful state-of-mind and put the child at-risk.

\section{Sensing Danger}

How does the sense of danger enable us to see more clearly the nature of taking risks? And how might this question make us more more mindful of children? Bledsoe (1977-1978) provides us with a clue in this regard when he reminisces about his own childhood fear of exploring a sewer system near his home.

The thought of that tunnel has come down to me many times over the years. In my mind I've tried to imagine what it would have been like further up the passageway from where I turned back. The tunnel seems to me to be an inescapable fact from my own biography and the experience is one that I have very often remembered. It is a thought that became central to my legend about going into darkness, into places that are shadowy, perilous and beckoning. When I think back on that time, I recall the anxiety-sitting there crouched between light and darkness. Later on, I was to learn that there is a phrase for it, that it is what is known as "the coming on of the night fear."

What stands out in my mind is the vividness of my original experiencethe encountering of the first crude sense of fear, but a sense of fear that was also tantalizing. For tied up in the memory as well is the not entirely unpleasant sense of latent danger, dark discovery, and uncertainty.

(p. 122) 
From this passage we gain the impression that Bledsoe never quite saw the risk that would impel him to explore the tunnel. By succumbing to his fear his anxiety was lessened, but at the expense of a less fearful relation to the world. As Heidegger (1962, p. 180) said, "what is detrimental as coming-close close by carries with it the latent possibility that it may stay away and pass us by; but instead of lessening or extinguishing our fearing, this enhances it." Like a fist raised in anger, we sense an impending danger. Something monstrous now stands before us and we dare not look to confirm our fears, especially when there is some comfort, cold though it may be, knowing it is at least somewhere beyond us. Nevertheless, the temptation becomes too great and we take a peek, a tentative step. Something stirs and we retreat. We withdraw to a dubious safety, even more fearful of that monstrous world outside. Our existence is threatened by the danger lurking there.

This disspiritedness, this surrender of the soul, is something we must look at more closely. Like children playing tag, there are those who give up too easily, not so much to be caught, but to be relieved of the tension of the game. If we choose to see these children as being of concern, then we are careful that when we ourselves chase the child we give him or her room in which to flee, although not so much room that we can ignore the child's desire to be caught and to feel the reassurance of our embrace. We realize that not to keep the child in close view is to endanger him or her and thereby to allow a sense of danger to become the motive for action. Being caught is in this instance not an eagerly awaited possibility but a sombre inevitability. Let us look at this possibility more closely through the example of the climb.

We are preparing to climb a mountain. For the past few days we, along with forty or so children, have been doing environmental studies, rock climbing, orienteering, canoeing and bushcraft; and throughout each activity we have spoken of the early explorers in the area, the routes they had taken and the settlements they had established. Ours is to be one such settlement for we are also explorers of this land. And all the while Mount Maroon stares down on us. Some sketch it, some photograph it, others find faces and forms within it-each anticipating in their own way the climb we are about to make.

The climb up Mount Maroon is not particularly difficult. Some sections require ropes, but for the most part it is a five hour hike and scramble to the top. Nevertheless we experience a peculiar discomfort. The children, except perhaps the "leaders," seem nervous. One of them, Chris, is scared by this mountain. His determination to reach the top is threatened by the fear he has for his safety. Each step pulls him away from where he feels comfortable. The glazed look in his eyes indicates that the mountain evokes a fear that prevents any attachment to the here and now. He does not see risk, but is overpowered by a sense of danger. Even on the descent when 
generally the worst is behind, still he sees danger. Still he winds his way down in a crab-like position, unaware even of the terrain levelling out, unaware of the others who stay with him, talking all the while about school, home and things (afraid that the seat of his pants must soon wear out). He maintains his posture of fear in spite of, and perhaps, because of the advances of those around him. Their words provide little comfort for, in a way, they continue to address the thought he has of danger and the fear he has for his safety.

To feel at relative ease requires that the terrain be seen as a landscape to be explored. The challenge is to extend the horizons of our actions and to risk a precarious identity for the sake of an identification with the world. On the other hand, if we continue to face this terrain as an entity in itself we inevitably lose our footing. Maybe we are too close. As through a close-up lens, the world is strange and menacing. An attachment is lost or never quite gained, and the terrain becomes a dangerous place to be. We see this in the fear that strikes when a slip is made as when rock hopping along a dry creek bed. We start leaping from one rock to another, unsure of where we are heading. Soon we are almost running in a more or less consistent direction. A pattern unfolds. We feel the texture of each rock, some corrugated, some worn smooth and slippery, and vary our pace accordingly. Then a thought occurs that we are going too fast-a moment of hesitancy - perhaps we are warned by those around us. Be careful!" they cry with a sense of impending danger. "Slow down or you'll hurt yourself!" Sure enough, we stumble, falling between a small crevice or bruise our shins on a rock that seems to rear up. A sense of danger now overpowers us. We've had enough of this activity and proceed very cautiously to some point of departure. This slip, like the slip in climbing, breaks the flow of the activity and plunges us into a state of anxiety. The risk that was seen in order to achieve some sense of the flow of the activity is now a danger to withdraw from. So we crouch down and detach ourselves from the things around us. What other options do we have?

One option we have is to learn the techniques that allow us to master, control and dominate the situation. We calculate our chances of surmounting the obstacles in front of us so that, instead of establishing a complicity with the world which would require our total engagement, our project becomes simply a making of the world. Calculating away the risk involved, we make a demand on the world which might very well detach us from the things out there. We contrive a danger to which we might respond in a technical, or rather, merely physical way. We lose sight of real physical existence, of the Aristotelian notion of physis, the internal principle of movement which is the essence of human nature (cf. Peters, 1967, pp. 158-160). As Marcel (1954) said when speaking out against the increasing tendency for techniques to become the "dynamic lineaments" of an "abstract world," the real danger is that we lose sight of "organic 
growth, and I am not thinking of that growth of the body, but of a feeling, of the becoming of the imagination in all its forms" (p. 12).

The element of danger becomes a significant feature of our activity not only because we have an implicit sense of it but also because it defines the sensible limits of our activity. For example, a cliff face can be graded for the purposes of climbing; however this calculation of danger does not necessarily eliminate the risks involved. To calculate away all risk completely is well-nigh impossible, yet one might well imagine such an attempt. "I climbed Ayers Rock" it says on a T-shirt, as if proclaiming the feat to the world. Others have also climbed Ayers Rock. In fact, thousands of people have mounted the steps that were cut into the Rock and stopped at various points along the way to admire the view from the security of the guard rail. What impoverished sense of risk this claim to have climbed Ayers Rock proclaims.

Efforts to calculate away risk broach a technological mode of revealing the things of the world, thereby denying us that involvement and commitment that is the real measure of risk taking. Such efforts are in danger of losing their authenticity as part of a truly physical mode of revealing the world to us. Heidegger (1977) intimated that by calculating away risks in such a manner we come "to the very brink of a precipitous fall" (p. 27). Though we stand seemingly apart from danger, it remains everpresent. In fact, the climber who has come to trust only the belay rope and the pitons that secure him to the cliff face needs only a slight miscalculation to actually experience "a precipitous fall." Danger prefigures his every move as he seeks dominance over the world around him. This strong sense of danger is not true to the physical disclosure of risk. It is at best a thrill. It is the roller coaster ride, the water slide, the powered boat ride. It is a way of confining ourselves within the boundaries of our own devices.

The sense of danger isolates us from the world; in particular, it isolates us from the world the child might come to know. Think again of the intensity Bledsoe must have felt when as a child he ventured far up the tunnel system near his home. We can almost sense how he must have been on the very brink, not of "a precipitous fall," but of a great discovery. This is not to say that there was no danger in Bledsoe's explorations and that he was not wise to go no further. But these "facts" should not be confused with the inevitable sense of danger that comes with turning back. The tunnel now stands out as a place of danger. What originally led somewhere, perhaps to an opening not far beyond where Bledsoe turned back, is remembered as the closing in of fear, as "the coming on of the night fear." Bledsoe says:

I carried something back down that sloping tunnel with me. It has existed there in my mind unnoticed, but now and then, over the years, it comes back to me. A shadow crosses my mind sometimes when I lie awake at night and I remember with bitterness that I hadn't gone in that 
tunnel all the way. I hadn't found out what had been around the first bend. Instead, I had been careful. (p. 122)

Compare this "bitterness" to the joy of the climber who is opened up to the landscape. A limited perspective is risked for the sake of securing a greater purchase on the world. The climber exemplifies the possibility of moving beyond the introspective domain where danger lurks to an appreciation of what taking a risk might entail. The climber exemplifies a different way of seeing Bledsoe's tunnel which is a way of being more mindful of children's experience of risk.

\section{Return to Landscape}

Climbing brings the world into view. It is symbolic of that tension that is actively sought between security and risk. Through climbing we see that a sense of security is in fact a venturing beyond the complacency of a no-risk situation. By way of contrast, think of looking to the top of a mountain and wishing only to take in the view as quickly as possible. In this case the value of the view from the top becomes the yardstick for our thoughts of getting there. The terrain is seen as an obstacle to be overcome, but not quite a hazard for then we would have difficulty keeping this end firmly in view. We have a picture in mind and project action well ahead of the here and now. Then, with the subsequent realization of the goal we see but a poor reflection of that which was imagined. "Was it worth the effort?" we ask somewhat rhetorically as the summit is finally reached. Van den Berg (1975) takes this contrast even further when he says that

Many of the people who, on their traditional trip to the Alps, ecstatically gaze at the snow on the mountain tops and at the azure of the transparent distance, do so out of a sense of duty. They are only imitating Rousseau; they are simulating an emotion which they do not actually feel. It is simply not permissible to sigh at the vision of the great views and to wonder, for everyone to hear, whether it was really worth the trouble. And yet the question would be fully justified; all one has to do is to see the sweating and sunburned crowd, after it has streamed out of the train or the bus, plunge with resignation into the recommended beauty of the landscape to know that for a great many the trouble is greater than the enjoyment. To a few the landscape is still delightful. But hardly anybody feels the delight is so great, so overpowering, that he is moved to tears. (p. 233)

Could this view warrant exposure to the risks of the climb? For those of us who wish only to take in the view there seems little point in taking unnecessary risks. The act of climbing itself seems to be a needless risk, even a sheer act of folly.

On the other hand, when taking in a view is related to the physical climb the value of risk taking comes to be appreciated. A view may be gained, for instance, by our climbing the difficult eastern face or by walking the gentle southern slope, yet somehow the presence of 
risk in climbing makes the world of difference. "It is worth it" is the response we make with each gesture toward the goal, because now the goal is part of the present activity. It has become real. The climb itself is part of the goal. The view from the top of the mountain reveals not only a landscape but the particular landscape of our climb. The view is uniquely seen. Our view is not that of the bushwalker, nor that of the sight-seer. Even though our visual field may be the same in each case, climbing provides a particular purchase on the world. We have made a view for ourselves insofar as where we will sit atop the mountain was prefigured in the very first climbing gestures we made and gained significance with each subsequent gesture. This idea of the view draws us upwards and gives significance to what has taken place and now occurs.

The risks of climbing are not hazards to be overcome. Nor do we take risks simply to respond to the mountain that dares to be climbed. In accepting challenge our view involves seeing the risks that make the challenge personally significant. We seek a deeper and stronger foothold, a higher and more stable vantage point. Through taking risks our place within the landscape is more fully understood. Climbing brings a recognition that "the world is given to me along with the parts of my body, not by any 'natural geometry', but in a living connection comparable, or rather identical, with that existing between the parts of my body itself" (Merleau-Ponty, 1962, p. 205).

We might speak therefore of a return to landscape so as to recognize this complicity of our risk taking with our sense of place in the world. There is, as it were, a "return to the ground of being" (Vandenberg, 1971, p. 205). Landscape is our worldliness. It is not so much a place in the here and now, as a primacy in our awareness of places and times. The fundamental landscape is the domain where the first affirmations of existence transpire. It is the place of childhood. Climbing rekindles the joyfulness, spontaneity and trust in the world which children first experience on the climbing frame in the park. Experiencing the natural world through climbing is a child-like reawakening to those now dim and distant feelings for one's place in the world. We recreate the primordial world that the child trusts; we recreate the openness of the child's relation to the world. Climbing, as a return to landscape, is a metaphor for our coming to see again in a child-like way.

\section{A Concern for Safety}

I see my child is afraid to climb the "jungle gym." What do I do? Do I let him work it out for himself? Do I cajole him to come down? I may be tempted to say "Look at Jamie. See, he can do it. You can do it too." But I know this dare may not work. It may not be appropriate. I know how high this frame stands for a child. The world looks so far below. And the metal bars are only a precarious connection between the high platform and the safe ground of the park. I have been a 
child and I know this fear. So what do I do?

There is, in this questioning of what I should do, a pedagogical admonition to be with the child as he or she ventures out into the world. Of course, some domains are not to be trusted and some equipment is simply unsafe, but these concerns are not the pedagogical concerns of our being with children, but those of child-minding. Care in framing the pedagogical situation grows out of the care that defines our own encounters with the things in our world. Such care avoids daring the child to see that which is unsafe and which would serve only to make the child totally dependent upon our care; it responds instead to the child's natural inclination to look more closely at things.

An overriding concern for the child's safety obscures the landscape in a most profound way. Not only does the world remain hidden but our stake in the world remains concealed. The emphasis on safety manifests the fears of adults who see danger lurking there and who are themselves afraid. For them taking a risk is not seeing the attachments which the world holds out, but sensing instead the possibilities of detachment. This is not a concern for the child but a concern for oneself. We request that the child "be careful" in order to direct the child to the risks involved in the activity at hand. But if this direction also suggests that the child takes care, as if he or she must see the activity as fraught with danger, then we must consider to what extent we have fulfilled our obligation to help the child such that his or her explorations are safe. This request for the child to "be careful" would seem to show less care in framing the activity than is required.

A pedagogical concern for safety means neither delimiting the boundaries of activity nor prescribing right ways of acting, but rather being with the child so that risks are seen where, without our help, danger might lurk. Pedagogy entails not so much looking out for the child's safety as caring sufficiently that his or her explorations can be carried out with an underlying sense of security. Within this perspective we are, for instance, up there on the climbing frame with the child for that child is like us. Though we stand below with outstretched arms and request the child to "be careful," in the spirit of the moment we revel with the child in the activity at hand. The child takes us up there with him or her, and in knowing we are there, climbing feels secure. "Watch me, Dad! Watch me!" the child says as he shimmies up the climbing frame, drawn like a magnet into the throng of children gathered there. Over the bars he moves, threading himself in and out of this wrought iron maze. Extricating himself momentarily he cries "Are you watching?!" Is this a question or a plea? There is a degree of apprehension in this child's voice. He calls again with greater urgency. "Are you watching?!" and with our reassuring nod he finds his place among the children. This child has nothing to show off but himself. He does not necessarily ask that we 
watch what he can do as if intent on giving us a performance. No, the child may want only to be watched, to feel the security of our protective gaze, to know that he is not alone. This cold metal frame full of unfamiliar faces needs a parental warmth.

If the child then becomes a little anxious on the climbing frame we ought not be unduly concerned for this anxiety is part of the child's coming to know the world in his or her own way. The child finds distance between the present context of activity and the world he or she knows. A risk is seen in shadowy outline. Our adult obligation, however, is to ensure that this anxiety does not separate the child from the things that are known, and in particular, from us. For example, we recall the child on the slippery slide refusing to come down on the seat of his pants, and we remember his plea that we come down with him. And on occasion we would climb up that ladder behind him, and then, with him nestling against us we would plummet down that slide. "Do it again" he pleads, but no, we think it is time he tried it by himself, after all, aren't we standing at the bottom ready to catch him? Similarly, we think of the child who will not go upstairs by himself - we must come with him. Do we help this child by laughing at his anxiety? Or does our help require us to go with him, to be with him as he comes to find the upstairs region increasingly familiar?

"Help me up" the child cries out, not even looking for ways he could pull himself up onto the climbing frame. He wants a boost, a reassuring hand, in order to get started. The child needs help before he is willing to help himself.

Because the safety of the world stands between his helplessness and his explorations, the child's access to the world exists through the help that others give him in establishing the safety of his world: he is cut off from his world unless he is helped. Authentic expansion of the child's world depends upon adults who are responsible for him, for if they engineer the safety of the world in proportion to his helplessness, they free him to explore an inviting world. (Vandenberg, 1971, p. 84)

The concern for safety can thus be seen to open up the horizons of risk provided we understand safety as a way of being with the child. While simply to make "things" safe is to draw the curtains of danger around the child's experience of the world, to consider safety as an admonition to be with the child while our help is required is to invite an expansion of the horizons of the familiar world. Through a sense of being-together the risks of the unfamiliar become a soliciting of our trust in the world. We do not risk this world as if putting it in danger, but rather, from our security we see risk as affording a way for trust to grow. Safety, as a being-with the child, discloses the deeper meaning of risk taking. 


\section{Responsibility}

An adult put the climbing frame in the park-the climbing frame around which a dare can take shape and through which we might see a child endangered. Taking care requires our support for the child as he or she explores this frame. It is not sufficient to make this "thing" safe. Care seeks to avoid a fearful state-of-mind where "what one "is apprehensive about" is one's Being-with the other, who might be torn away from one" (Heidegger, 1962, p. 181). Care requires being with the child such that we might come to see ourselves on the climbing frame. This is not mere empathy. It requires our becoming child-like, reawakening to the landscape of the child. Such care involves a responsibility for the child.

This responsibility can be spoken of as a way of seeing pedagogically. For instance, we realize that to expect the child to feel comfortable on the climbing frame, the slippery slide, even the mountain, without our being with him or her, is to expect too much of the child and too little of ourselves. In this case we do not fully appreciate the risks involved and through our irresponsibility we make the world dangerous for the child. From this position of being detached from the child there would be little difference between say the slippery slide and the mechanical ride, or between climbing a metal frame and climbing a mountain. The difference is appreciated only when we adopt a child-like perspective, which is to say, when we re-member the child in the activities we can share. Consider in this regard the very young child who is playing pony on our leg. She giggles each time we bounce her into the air and delights us with her happiness. She allows us to see things with a certain freshness and shows us a joy in being alive. And so we bounce her higher and higher, ever mindful of the limits of her trust. Yet this is the same child who cries and clings to us when we put her on a mechanical donkey at the local shopping mall. This child asks us to be responsible for her.

Perhaps the child who resists the world deserves more than our dare. Fears inevitably arise, but what is of concern to us is the habit of backing away that arises out of fear. The pedagogical admonition is to see the risk that gives way to fear so that the child's response is not a backing away from danger but a drawing toward the world. We see this risk by being-with the child as if returning to the landscape of our childhood. Seeing a risk responsibly is in these terms a disclosure of our world and a disclosure of the child's place within it. When we speak therefore of seeing a risk we are speaking fundamentally of a pedagogical venture in which a child-like nature can be afforded space to unfold. 


\section{References}

Bledsoe, J. (1977-1978). The world of the cave kid: The rightful recognition of children's knowledge. Interchange, 8(1-2), 119-127.

Csikszentmihalyi, M. (1975). Deep play and the flow experience in climbing. Beyond boredom and anxiety: The experience of play in work and games (pp. 74-101). San Francisco: Jossey-Bass.

Heidegger, M. (1962). Being and time. Oxford: Blackwell.

Heidegger, M. (1977). The question concerning technology and other essays. New York: Harper and Row.

Marcel, G. (1954). The decline of wisdom. London: Harvill.

Merleau-Ponty, M. (1962). Phenomenology of perception. London: Routledge and Kegan Paul.

Peters, F.E. (1967). Greek philosophical terms: A historical lexicon. New York: New York University Press.

Roche, M. (1980). The life of sport: An analysis. Maieutics, 1(1), 63-93.

Shipley, J.T. (1959). Dictionary of word origins. Ames, IO: Littlefield Adams.

Van den Berg, J.H. (1975). The subject and his landscape. The changing nature of man. New York: Dell.

Vandenberg, D. (1971). Being and education. Englewood Cliffs, NJ: PrenticeHall.

Weekley, E. (1924). A concise etymological dictionary of modern English. New York: Dutton. 